\title{
The effects on locomotor activity and reactivity of the hypoactive and inactive mutations of Drosophila melanogaster
}

\author{
Kevin O'Dell* and \\ Barrie Burnet
}

Department of Genetics, University of Sheffield, Sheffield S10 2TN.

Locomotor activity, expressed as walking and running, is reduced in adult flies by the mutant genes inactive, inactive ${ }^{2}$, hypoactive- $C$ and hypoactive- $E$. The mutations iav and hypo $C$ reduce both the amount and speed whereas hypoE reduces the speed but not the amount of locomotion. Stimulated activity, reactivity, and spontaneous activity are affected in different ways by these mutations. The frequency of jumping is greatly reduced by all four mutations, and the threshold for the jumping response appears to be related to speed of locomotor activity. The developmental profiles for locomotor activity of hypoactive and inactive mutants is described.

\section{INTRODUCTION}

Several mutations have been isolated on the basis of aberrant locomotor activity. The inactive mutation was described by Kaplan (1977). Seven nonallelic hypoactive mutations, described by Homyk and Sheppard (1977) and Homyk et al. (1980), were isolated using a screen for mutants of reduced flight ability. Homyk (1977) described the hypoactive subset of these mutants as difficult to arouse into the excited state necessary for flight. They have low spontaneous activity and soon become inactive following any disturbance that has excited them. O'Dell and Burnet (1986) reported that the mutant genes hypoactive- $B$ and inactive are alleles.

Changes in the level of expression of the activity of an individual over a short time period have been attributed to reactivity, but the links have yet to be worked out between reactivity, and spontaneous activity expressed when a fly is in a settled state. Individuals may show an initially high level of activity in response to disturbance which Meehan and Wilson (1987) refer to as stimulated activity. Connolly (1967) used a measure of reactivity based on repeated sampling of the behaviour of a fly after transfer to constant conditions. Individuals ceased to respond to extraneous features of the environment as they attained a

\footnotetext{
* Present address: Genetics Laboratory, Department of Biochemistry, University of Oxford, South Parks Road, Oxford OX1 3QU.
}

settled state. He used the rate of change in activity as a measure of reactivity. Differences in the expression of reactivity in lines selected for changes in locomotor activity have indicated that spontaneous activity and reactivity are at least partially under the control of different genes (Connolly, 1967; van Dijken, 1982). More recently Burnet et al. (1988) partitioned locomotor activity into two independent but related measures of amount and speed which, though correlated, were also found to differ in their underlying genetic control. Flies reacted to disturbance by a startle response characterised by jumping, increased speed of locomotion, and a reduced rate of preening. Their reactivity was found to be expressed more in terms of changes in speed than amount of movement.

Longer-term changes in activity have been investigated in connection with circadian rhythm mutations such as period (Konopka and Benzer, 1971) which is perhaps the most intensively studied behavioural mutation in Drosophila (Ashburner, 1987; Yu et al., 1987). Rather less attention has been directed towards developmental changes in locomotor activity, although Cobb et al. (1987) found a relationship with age in their comparative study of different species of the melanogaster species subgroup.

Neurological mutations could potentially affect one or more of the different aspects of expression of locomotor activity in Drosophila, and detailed 
description of their effects is a first step toward recognising groups of genes involved in control of specific functional systems. Here we describe the effects of three such genes hypoactive- $C$, hypoactive- $E$ and inactive (hypoactive- $B$ ).

\section{MATERIALS AND METHODS}

The Novosibirsk isogenic inbred wild type stock has been kept under a system of full sib mating for many years (Eastwood and Burnet, 1977). The Sierra Leone Isogenic inbred wild type (line 23) stock was derived from a single wild caught female and has been maintained under constant brother sister mating since 1982 .

Inbred strains hypoactive- $C^{1}$, hypoactive- $E$ and inactive $^{2}$ (formerly hypoactive- $B^{1}$, O'Dell and Burnet, 1986) all share an Oregon- $R$ wild type background. They were isolated by Homyk and Sheppard (1977), and Homyk et al. (1980). Further information about the mutant genes is given by Hall (1982), and by Lindsley and Zimm (1985).

The inactive strain is described by Kaplan (1977). Two isogenic inbred stocks, Novosibirsk iav and Sierra Leone iav, were synthesised. The mutant allele iav $(\mathrm{X}: 18 \cdot 8)$ was first incorporated by crossing-over into a multiply marked first chromosome: yiavvfcar. Using inversioncontaining balancer chromosomes with dominant marker genes the homozygous autosomal background of each of the isogenic wild type stocks was then constructed round the multiply marked $\mathrm{X}$-chromosome. The iav mutant allele was then transferred from the multiply marked $X$ into the appropriate wild type first chromosome background by crossing-over. Serial backcrossing into the corresponding isogenic inbred wild type strain and reisolation of the iav mutant allele was then carried out over several generations to yield inactive strains with the same associated genetic background as the wild type allele. These were designated Niav ${ }^{+}$and Niav ${ }^{-}$, and Siav ${ }^{+}$and Siav ${ }^{-}$.

For the analysis of reactivity (figs. 1 and 2) the original inactive stock of Kaplan (1977) was used. Reciprocal $F_{1}$ hybrids between the isogenised stocks NSiav ${ }^{+}$, and SNiav ${ }^{+}$, also between NSiav ${ }^{-}$ and $\mathrm{SNiav}{ }^{-}$, were used for analysis of age-related changes (figs. 3 and 4). Analyses of variance revealed no statistically significant differences between the reciprocals so the results were pooled for further analysis.

Stocks were maintained at $25 \pm 0.5^{\circ} \mathrm{C}$ on a $12: 12$ hour night day cycle at constant humidity on standard oatmeal and treacle medium seeded with live bakers yeast. Sexes were separated within six hours of eclosion and kept in groups of 10-12 individuals. Flies kept for effects of age were transferred to fresh food vials on alternate days. On the day preceding each behavioural trial all flies were transferred to fresh food vials, and behavioural observations were made in the constant temperature room in which the flies were cultured.

Locomotor activity was observed in an open field chamber $(10 \times 10 \times 1 \mathrm{~cm})$ made of white perspex fitted with a clear lid engraved with a grid of $1 \times 1 \mathrm{~cm}$ squares. A single fly was transferred into the chamber through a closable entry port using an aspirator. The chamber was then tapped 10 times in quick succession before beginning observations. Behaviour was recorded using an Apple II microcomputer interfaced with manually operated keyboards. The frequency and duration of key presses on each independent channel was continuously recorded.

The amount of movement was computed as the proportion of time spent moving in each successive minute of the observation period and then transformed to angles (arcsine). Speed of movement is calculated from the number of squares entered. Weighting is necessary because differences in the amount of time spent moving affects the accuracy of the speed score. For a group of $r$ individuals the mean weighted speed $s$ is calculated as the mean number of squares entered $d$ divided by the untransformed mean time spent moving $t$. Because the mean speed score is actually a ratio estimator its standard deviation is:

$$
\frac{d}{t} \sqrt{\frac{\operatorname{var} d}{d}+\frac{\operatorname{var} t}{t}-2 \frac{\operatorname{cov} d t}{d t}}
$$

where var $d$ is the variance of $d$, var $t$ is the variance of $t$, and cov $d t$ is the covariance of $d t$. The standard error follows in the usual way.

For analysis of age-related changes in activity the flies were given a settling down period of $5 \mathrm{~min}$ after entry into the observation chamber. Activity was then recorded for the following $5 \mathrm{~min}$.

In this manner locomotor activity was scored at six ages: 1, 2, 4, 8, 16 and 32 days old. In any session, 145 -min trials were conducted using male and females from seven genotype groups: hypoC, hypoE, iav ${ }^{2}, \mathrm{NSiav}^{+}, \mathrm{SNiav}{ }^{+}, \mathrm{NSiav}^{-}$and SNiav ${ }^{-}$. Within each age group a single set of 14 trials was completed in a two and a half hour session during the afternoon. Ten replications of each age group were made over a period of three months. 
A problem associated with attempting to record activity in older flies is the variation in survival observed between the wild type and mutant stocks. The hypoC females show a particularly poor rate of survival. Observations on the hypoC, hypoE and $i a v^{2}$ mutants were not continued to 32 days of age for this reason.

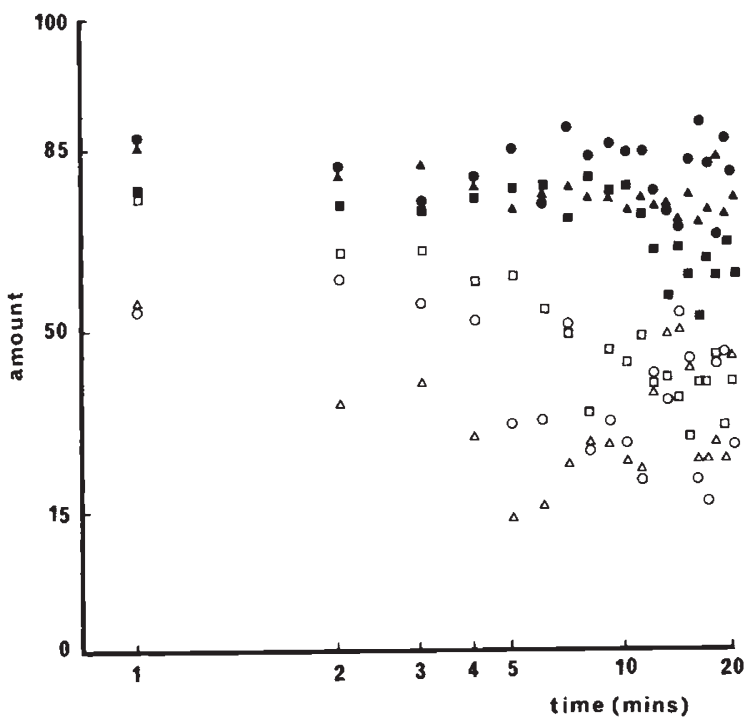

Figure 1 Amount of movement by female flies. Novosibirsk wild type $\boldsymbol{\Delta}$, Sierra Leone wild type $\square$, hypoactive- $C \square$, hypoactive-E inactive $\bigcirc$, and inactive ${ }^{2} \Delta$.

\section{RESULTS}

\section{Amount and speed of movement}

Locomotor activity of female flies observed singly in an open field activity chamber is shown in fig. 1. Wild type flies (Novosibirsk and Sierra Leone) and hypoactive- $E$ mutants were similar in that the amount of movement remained relatively stable over the first $10 \mathrm{~min}$ of the observation period then became more variable in the period $10-20 \mathrm{~min}$.

Regression constants in table 1 provide an estimate of the mean initial amount of movement during min 1 after disturbance on entry into the observation chamber. They show that these three stocks were initially similar. The amount of movement of hypoE mutant females remained steady over the full $20 \mathrm{~min}$ observation period whereas the regression coefficients for the wild types showed a small but significant decline in movement with time.

The hypoactive- $C$ mutants moved as much as the wild types initially but they became less active during the first $10 \mathrm{~min}$ and reached a lower level in the period $10-20 \mathrm{~min}$, significantly below that of the wild types.

In the first minute of observation females homozygous for the inactive or inactive ${ }^{2}$ mutant alleles spent less time in locomotion than flies of any of the other genotype groups. The amount of movement declined during the first $10 \mathrm{~min}$. In the succeeding period $(10-20 \mathrm{~min})$ the amount of movement was rather variable around what appears to be a settled level significantly lower than that for hypoE and the wild types.

Table 1 shows the regression constants and coefficients for amount of movement over $10 \mathrm{~min}$ for the strains hypoC, $i a v$ and $i a v^{2}$ and for the three hybrid strains derived from crosses between them. These may be compared with the values for hypoE and the two inbred wild type strains computed over a $20 \mathrm{~min}$ period, as shown in fig. 1 . Heterozygotes for hypoC/iav and hypoC/iav ${ }^{2}$ show a high initial amount of movement and a small but significant fall over time $\left(\right.$ hypoC/iav $\left.{ }^{2}\right)$, or no significant change (hypoC/iav). Heterozygotes for the allelic mutations $\left(i a v / i a v^{2}\right)$ have a

Table 1 Regression constants and coefficients for change in the amount and speed of locomotion. $P$ denotes the associated probability that the regression slope differs from zero due to chance

\begin{tabular}{|c|c|c|c|c|c|c|}
\hline & \multicolumn{3}{|c|}{ Amount of locomotion } & \multicolumn{3}{|c|}{ Speed of locomotion } \\
\hline & Constant & Coefficient & $P$ & Constant & Coefficient & $P$ \\
\hline$i a v$ & $0.9534 \pm 0.0844$ & $-0.4041 \pm 0.1168$ & $<0.01$ & $0.4208 \pm 0.0290$ & $-0 \cdot 1068 \pm 0 \cdot 0401$ & $<0.05$ \\
\hline$i a v^{2}$ & $0.7655 \pm 0.0764$ & $-0 \cdot 3753 \pm 0 \cdot 1058$ & $<0.01$ & $0 \cdot 4068 \pm 0 \cdot 0149$ & $-0.0477 \pm 0.0207$ & $<0.05$ \\
\hline hypoC & $1 \cdot 1385 \pm 0.0515$ & $-0.4461 \pm 0.0714$ & $<0.001$ & $0.6059 \pm 0.0310$ & $-0.1520 \pm 0.0429$ & $<0.01$ \\
\hline$i a v / i a v^{2}$ & $0.9910 \pm 0.0678$ & $-0.4344 \pm 0.0938$ & $>0.01$ & $0.5216 \pm 0.0321$ & $-0.0446 \pm 0.0444$ & ns \\
\hline$i a v / h y p o C$ & $1 \cdot 1732 \pm 0.0292$ & $-0.0329 \pm 0.0404$ & ns & $1 \cdot 5398 \pm 0.0530$ & $-0.2140 \pm 0.0734$ & $<0.05$ \\
\hline$i a v^{2} /$ hypoC & $1 \cdot 2643 \pm 0 \cdot 0205$ & $-0 \cdot 1281 \pm 0 \cdot 0284$ & $<0.01$ & $1 \cdot 3400 \pm 0.0424$ & $-0.1017 \pm 0.0587$ & ns \\
\hline hypoE & $1 \cdot 1968 \pm 0 \cdot 0181$ & $-0.0277 \pm 0.0184$ & ns & $0.4524 \pm 0.0064$ & $-0.1197 \pm 0.0065$ & $<0.001$ \\
\hline Novosibirsk & $1 \cdot 1906 \pm 0 \cdot 0080$ & $-0.0900 \pm 0.0081$ & $<0.001$ & $1 \cdot 1628 \pm 0.0132$ & $-0 \cdot 1560 \pm 0 \cdot 0135$ & $<0.001$ \\
\hline Sierra Leone & $1 \cdot 1964 \pm 0.0190$ & $-0 \cdot 1919 \pm 0.0193$ & $<0.01$ & $1 \cdot 1588 \pm 0 \cdot 0123$ & $-0.0261 \pm 0.0128$ & n.s. \\
\hline
\end{tabular}


low initial level of activity similar to iav homozygotes. Regression coefficients, which reflect decay of activity over time, are similar for hypoC, iav, and $i a v^{2}$ homozygotes, and $i a v / i a v^{2}$ heterozygotes.

There is a clear dichotomy between wild types and mutants for speed of locomotion (fig. 2). The regression constants, which estimate initial speed of locomotion, are similar for the two wild type strains (table 1). Sierra Leone females showed no significant change in speed over the $20 \mathrm{~min}$ observation period, whereas speed of the Novosibirsk females decreased significantly. Speed of locomotion of all four mutant strains was initially less than half that of the wild types, and tended to decrease towards a settled level. The regression coefficients in table 1 show that this reduction in speed with time is significant for each of the hypoactive and inactive mutants but not for the heterozygote $i a v / i a v^{2}$.

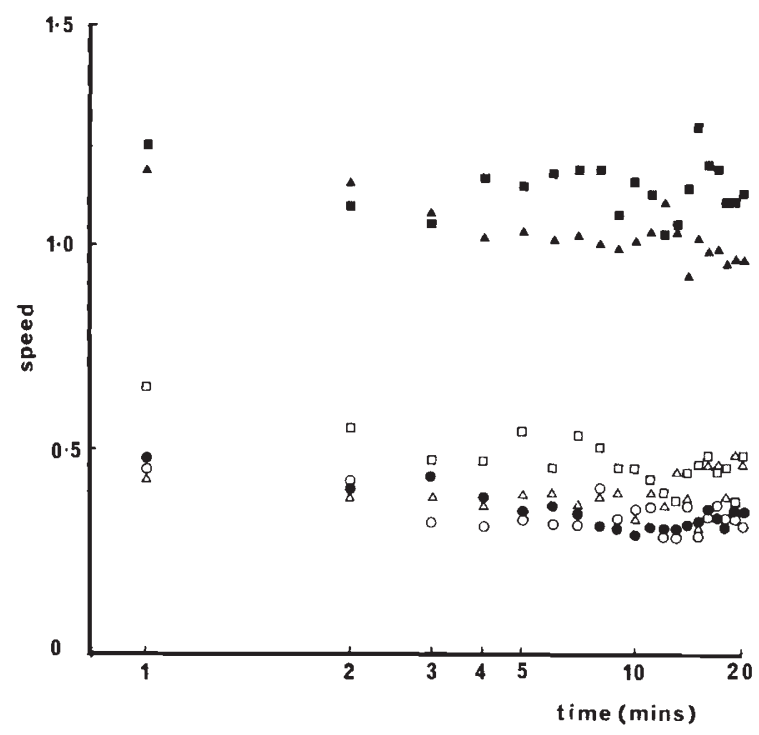

Figure 2 Speed of iocomotion by female flies. Novosibirsk wild type $\boldsymbol{\Delta}$, Sierra Leone wild type $\square$, hypoactive $C \square$, hypoactive-E , inactive $\bigcirc$, and inactive ${ }^{2} \triangle$.

\section{Developmental profile of locomotor activity}

Fig. 3 shows the mean expression of predominantly settled activity in relation to age. Wild type flies of both sexes exhibited a steady decline in the amount of movement with age from day 1 to day 32. The inactive flies reached a maximum activity at day 2 but thereafter, there was a fall in activity until day 32 . There were no statistically significant differences in the amount of time spent moving as between males and females of the same genotype group. Consequently observations were pooled for the analysis of variance in table 2 which confirms the significance of differences in amount of locomotion between genotypes. The inactive flies are consistently less active than wild type at all ages. In the wild type group the reduction in activity below the level at day 1 is significant at day 8 . Increase in activity of inactive flies between day 1 and 2 is not significant, but the decrease from the peak reached at day 2 is significant at days 8,16 and 32 .

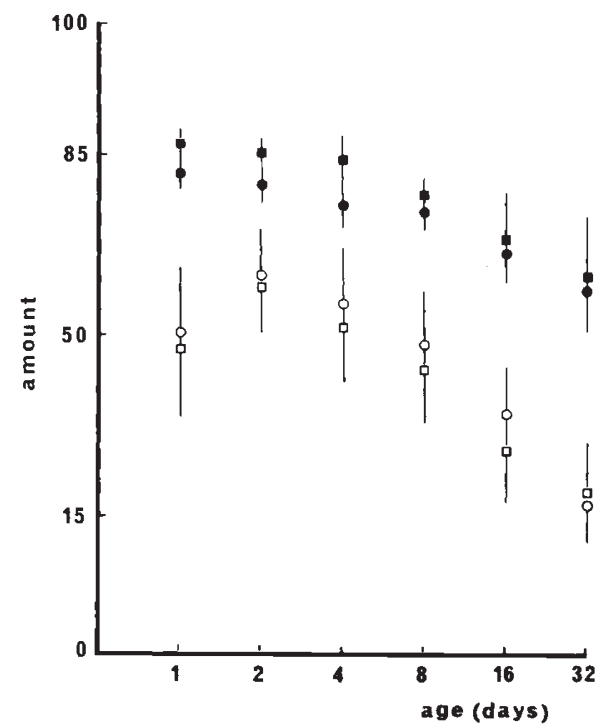

Figure 3 Change in amount of movement with age. Wild type males $\square$ and females $\bigcirc$, inactive males $\square$ and females $\bigcirc$. Each point represents the mean \pm standard error.

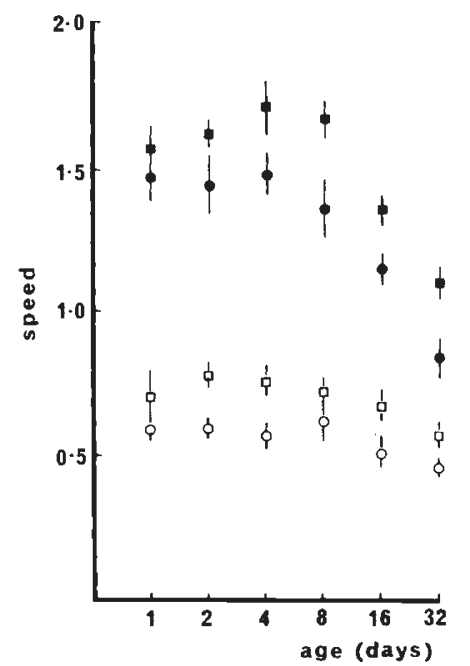

Figure 4 Relationship between age and speed of movement. Wild type males $\square$ and females $\bigcirc$, inactive males $\square$ and females $O$. Each point represents the mean \pm standard error. 
Table 2 Analysis of variance for effects of age and genotype on amount of movement by wild type and inactive flies

\begin{tabular}{|c|c|c|c|c|c|c|}
\hline \multirow[b]{2}{*}{ Source } & \multicolumn{3}{|c|}{ Males } & \multicolumn{3}{|c|}{ Females } \\
\hline & $\mathrm{df}$ & $\mathrm{ms}$ & $F$ & $\mathrm{df}$ & $\mathrm{ms}$ & $F$ \\
\hline Genotype & 1 & $11 \cdot 86$ & $107 \cdot 6^{* * *}$ & 1 & 6.928 & $75 \cdot 6^{* * *}$ \\
\hline Age & 5 & 1.024 & $9 \cdot 3^{* * *}$ & 5 & 0.955 & $10 \cdot 4^{* * *}$ \\
\hline Interaction & 5 & 0.053 & 0.5 & 5 & 0.116 & $1 \cdot 3$ \\
\hline Error & 228 & $0 \cdot 110$ & & 228 & 0.092 & \\
\hline Total & 239 & & & 239 & & \\
\hline
\end{tabular}

*** Denotes value of $F$ significant at $P<0.001$.

Table 3 Analysis of variance for the effects of age on the speed of locomotion of wild type and inactive flies

Wild type

\begin{tabular}{|c|c|c|c|c|c|c|}
\hline \multirow[b]{2}{*}{ Source } & \multicolumn{3}{|c|}{ Males } & \multicolumn{3}{|c|}{ Females } \\
\hline & $\mathrm{df}$ & $\mathrm{ms}$ & $F$ & $\mathrm{df}$ & $\mathrm{ms}$ & $F$ \\
\hline Age & 5 & $1 \cdot 300$ & $27 \cdot 2^{* * *}$ & 5 & $1 \cdot 610$ & $32 \cdot 0 * * *$ \\
\hline Error & 112 & 0.048 & & 114 & 0.050 & \\
\hline \multicolumn{7}{|l|}{ Inactive } \\
\hline Source & $\mathrm{df}$ & $\mathrm{ms}$ & $F$ & $\mathrm{df}$ & $\mathrm{ms}$ & $F$ \\
\hline Age & 5 & $0 \cdot 117$ & $3 \cdot 3^{* *}$ & 5 & $0 \cdot 172$ & $9 \cdot 0 * * *$ \\
\hline Error & 98 & 0.036 & & 102 & 0.019 & \\
\hline
\end{tabular}

*** and ** denote values of $F$ significant at $P<0.001$ and $P<0.01$, respectively.

Fig. 5 shows that the amount of movement by hypoactive- $E$ mutants was comparable to that of wild type flies at 1-16 days of age, and shows a similar age related decrease (cf. fig. 3 ). The $i a v^{2}$ strain was the least active at each age, and hypoC mutants were consistently intermediate until day 16 at which there was overlap with $i a v^{2}$. Analysis of variance (table 4) confirms significant differences in the amount of movement between these genotype groups. There were significant differences in activity with age, and also interaction reflecting the increase in amount of movement between days 1 and 2 in hypoC and $i a v^{2}$ which was not observed in the hypoE mutants.

Speed of locomotion was significantly higher in males than in females in all genotype groups. The inactive mutants were significantly slower than wild type at all ages up to 32 days after eclosion (fig. 4). Wild type flies got slower as they aged from day 8 onwards (table 3 ), whereas inactive mutants showed a significant but less pronounced age-related change.

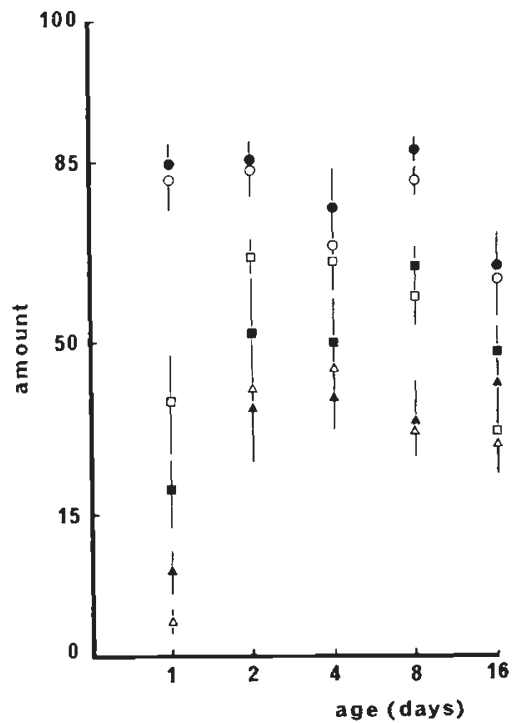

Figure 5 Change in amount of movement with age. hypoactive$C$ males $\square$ and females $\square$, hypoactive- $E$ males $\square$ and females $O$, inactive ${ }^{2}$ males $\Delta$ and females $\Delta$. 


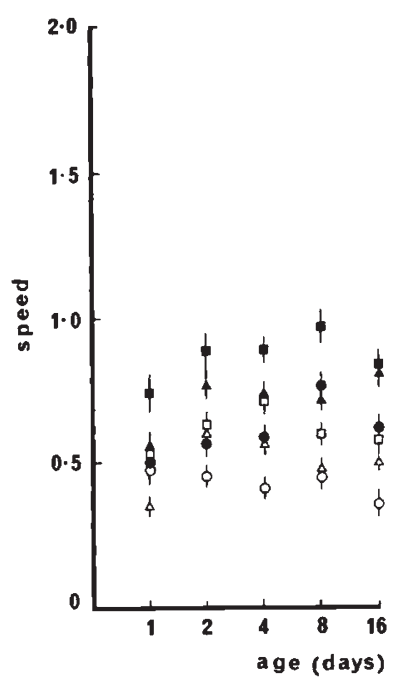

Figure 6 Relationship between age and speed of movement. hypoactive- $C$ males $\square$ and females $\square$, hypoactive- $E$ males - and females $\bigcirc$, inactive ${ }^{2}$ males $\Delta$ and females $\triangle$.

The mutant alleles hypoC, hypoE and $i a v^{2}$ cause reduced speed of movement at all ages from day 1-16 (fig. 6). In both sexes the mutants differed significantly from one another in speed (table 5). The hypoE mutants are the slowest flies. The speed of movement of hypoC and $i a v^{2}$ flies increased between days 1 and 2 in concert with the increase in amount of movement (fig. 5), suggesting that the processes underlying the developmental profiles for activity of these two mutants are linked.

\section{Jumping}

Flight is constrained by the low roof of the observation chamber so that jumping, most frequently observed during the first three minutes after disturbance, may sometimes actually be aborted takeoff. Jumping is one facet of a startle response reflecting a high state of excitation (Burnet et al., 1988). Over a 5 min observation period mutant flies of both sexes jumped significantly less frequently than wild type flies (fig. 7). The marked dichotomy between wild-type and mutant flies suggests that the threshold of excitation associated with jumping is infrequently attained in mutant flies. The attenuation of jumping which occurs in hypoE mutants implies that the threshold for expression of jumping is in some way correlated with speed of locomotion, because they are abnormally slow (fig. 2), whilst they are indistinguishable from wild type in amount of movement (fig. 1).

The frequency of jumping was sustained at a very low level as age increased in inactive and hypoactive mutants. Wild type flies showed significant age related change from high frequency between days $1-8$, falling thereafter to negligible frequency similar to that in the mutants.

Table 4 Analysis of variance for the effects of age and genotype on amount of movement by hypoactive-C, hypoactive-E, and inactive ${ }^{2}$ flies

\begin{tabular}{|c|c|c|c|c|c|c|}
\hline \multirow[b]{2}{*}{ Source } & \multicolumn{3}{|c|}{ Males } & \multicolumn{3}{|c|}{ Females } \\
\hline & df & $\mathrm{ms}$ & $F$ & df & $\mathrm{ms}$ & $F$ \\
\hline Genotype & 2 & $4 \cdot 75$ & $54 \cdot 3^{* * *}$ & 2 & $4 \cdot 29$ & $61 \cdot 2^{* * *}$ \\
\hline Age & 4 & 0.446 & $5 \cdot 1^{* * *}$ & 4 & 0.639 & $9 \cdot 1^{* * *}$ \\
\hline Interaction & 8 & $0 \cdot 224$ & $2 \cdot 6^{*}$ & 8 & 0.278 & $4 \cdot 0^{* * *}$ \\
\hline Error & 135 & 0.088 & & 135 & 0.070 & \\
\hline
\end{tabular}

*** and ${ }^{*}$ denote values of $F$ significant at $P<0.001$ and $P<0.05$, respectively.

Table 5 Analysis of variance for the effects of genotype on speed of locomotion of hypoactive-C, hypoactive- $E$ and inactive ${ }^{2}$ flies

\begin{tabular}{|c|c|c|c|c|c|c|}
\hline \multirow[b]{2}{*}{ Source } & \multicolumn{3}{|c|}{ Males } & \multicolumn{3}{|c|}{ Females } \\
\hline & $\mathrm{df}$ & $\mathrm{ms}$ & $F$ & $\mathrm{df}$ & $\mathrm{ms}$ & $F$ \\
\hline Genotype & 2 & 0.600 & $16 \cdot 9^{* * *}$ & 2 & $0 \cdot 289$ & $18 \cdot 1^{* * *}$ \\
\hline Error & 139 & 0.035 & & 139 & 0.016 & \\
\hline
\end{tabular}

*** denotes values of $F$ significant at $P<0 \cdot 001$. 


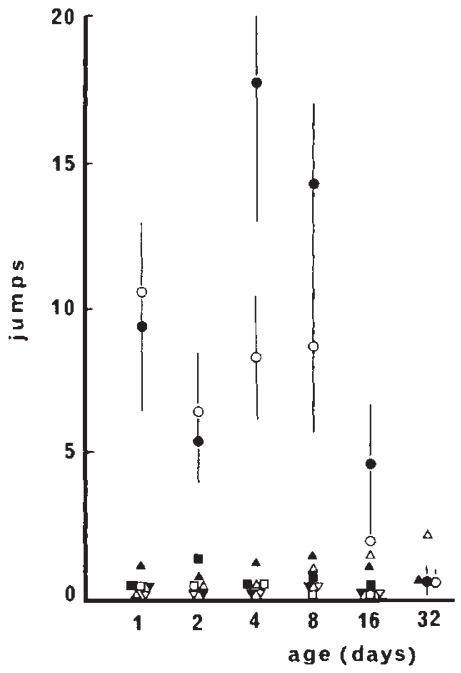

Figure 7 Change in amount of jumping with age. Each point represents the number of jumps measured over a $5 \mathrm{~min}$ period. Wild type males and females $O$, hypoactive- $C$ males $\square$ and females $\square$, hypoactive males $\nabla$ and females $\nabla$, inactive males $\boldsymbol{\Delta}$ and females $\Delta$.

\section{DISCUSSION}

There is a clear distinction between the mutations iav and hypoC, which affect both the amount and speed of adult locomotor activity, and hypoE which affects only speed of locomotion, so that it is perhaps more appropriate to describe the phenotype of hypoE mutants as slow rather than hypoactive. This difference, together with the observation that males and females differ significantly for speed, but not amount, of locomotor activity, supports the conclusions of Burnet et al. (1988) that amount and speed of locomotion are largely under independent genetic control.

Cobb et al. (1987) using the same measure of adult activity as that previously used by Connolly (1967) observed sex differences within different species of the Drosophila melanogaster species subgroup. Since this measure confounds two largely independent components, only one of which shows significant sex differences in D. melanogaster, it is probable that the species differences described by Cobb et al. (1987) are largely due to differences in speed rather than amount of locomotion.

Reactivity is a kinesis in the sense that it expresses itself as a change in the rate of locomotor activity measured in terms of amount or speed of locomotion (Schöne, 1984). In the present context the magnitude of the response to disturbance is reflected by the initial response and by the rate of decay towards a settled or spontaneous level. Meehan and Wilson (1987) regard the initial response, which they term stimulated activity, as a category of locomotor activity distinct from spontaneous activity and reactivity. van Dijken et al. (1987) measured locomotor activity in adult $D$. melanogaster in a locometer, an apparatus which represents a modification of the method used by Ewing (1963). Reactivity was defined as the regression of locomotor activity on density, using groups of individuals of varying size. From an analysis of the effects of different combinations of homozygous chromosomes derived from selected lines van Dijken (1982) concluded that spontaneous activity and reactivity to other flies of the same sex are at least partially controlled by different genes.

Wild type flies show a relatively low rate of decay in amount and speed of locomotion over a 10 min period below the level of initial response. The mutations iav and hypoC cause a rapid decay in amount of movement, and to this extent are less reactive than wild type. However the mutations differ in their effects on the magnitude of stimulated activity which is not affected by hypoC but is depressed by iav. The hypoE mutation causes no change in expression of reactivity as expressed through amount of movement. The effects of iav are the reverse of those of the Tyr-1 mutation which causes an increase in stimulated activity (Meehan and Wilson, 1987). All three mutant genes attenuate the initial speed of locomotion, but the rates of change measuring reactivity are essentially similar to wild type. These findings show that stimulated activity, reactivity, and spontaneous activity may be separately distinguished in terms of amount and speed of locomotion, and that different mutant genes affect the separate aspects of activity in different ways.

Although at separate gene loci, the iav and hypoC mutations are remarkably similar in their range of phenotypic effects. Homyk (1977) has located different mutant foci for these mutations in the thoracic and suboesophageal ganglia using mosaic mapping procedures. However, as Hall (1985) has pointed out, since the mapping procedures depended upon mutant versus normal tissues only with respect to the external cuticle, and without additional internal markers, only indirect inferences are possible with respect to the neural defects. An extension of the search for the foci of these mutations, and of that for hypoE, using internal tissue markers may provide further evidence concerning their mode of action. O'Dell 
et al. (1987) have detected a significant deficit in octopamine levels in iav mutants. Whether this reflects a direct effect of the iav gene, or an indirect consequence of reduced locomotor activity is as yet unclear. This is additional prima facie evidence that the iav mutation has a neural focus. It is not yet known what effect, if any, the hypoactive mutations may have on octopamine titres. The Tyr-1 mutation is associated with a reduction in dopamine levels (Burnell and Daly, 1982). Altered catecholamine balances may be a mechanism linking the effects of all of these mutations on differing aspects of locomotor activity.

Mutations which have been found to cause abnormalities of the jumping response are bendless (Thomas, 1980; Thomas and Wyman, 1982), jumpless (Hall, 1982), and non-jumper (Thomas, 1980), which are associated with abnormalities affecting the giant nerve fibre. Another mutation, acclinal (Deak, 1976) has an unknown focus. The threshold of reactivity necessary for induction of the jumping response is rarely attained in inactive and hypoactive flies at all ages, whereas wild type flies exhibit a clear age-related profile in which the jumping response shown by younger flies steadily declines with age. The near absence of a jumping response by hypoE females suggests that the threshold for this activity may be associated with the mechanism controlling speed of locomotion.

Wild type flies show a developmental profile with respect to amount and speed locomotion characterised by high levels of expression during days 1-8 after eclosion from the pupa followed by decay in the levels of expression through days 16-32. Actually, the high levels of activity in wild type flies at one day of age preceded by significantly lower levels of expression on the day of eclosion (O'Dell and Jallon, unpub.). The developmental trajectory in locomotion by hypoE mutants resembles that of wild type, whereas the iav and hypoC mutations appear to effect a change in the developmental profile by causing a delay in attaining the age-related maximum, without apparently postponing a decay of expression in older flies. Leffelaar and Grigliatti $(1980 a, b)$ argued that the characteristics of developmental profiles of specific behaviours may aid genetic studies of premature ageing. In their search for adult lethal mutations which exert their effects by accelerating the ageing process, they pointed out that there are few behaviours in Drosophila that are consistently age related. Further studies on the developmental profiles of wild type adult locomotor activity as described here may prove informative in that context.
Acknowledgement This investigation was carried out during tenure by K. O'Dell of a postgraduate training award from the Science and Engineering Research Council, U.K.

\section{REFERENCES}

ASHBURNER, M. 1987. Love-song and circadian rhythm. Nature, 326, 741 .

BURNELL, A. M. AND DALY, B. A. 1982. Spontaneous activity and dopamine levels in Tyr-1 mutants of Drosophila melanogaster. In Lakovaara, S. (ed.), Advances in Genetics, Development and Evolution of Drosophila, Plenum, New York.

BURNET, B., BURNET, L., CONNOLLY, K. AND WILLIAMSON, N. 1988. A genetic analysis of locomotor activity in Drosophila melanogaster. Heredity, 61, 111-119.

COBB, M., CONNOLLY, K. AND BURNET, B. 1987. The relationship between locomotor activity and courtship in the melanogaster species sub-group of Drosophila. Anim. Behav., 35, 705-713.

CONNOLLY, K. 1967. Locomotor activity in Drosophila III. A distinction between activity and reactivity. Anim. Behav., $15,149-152$.

DEAK, I. I. 1976. Use of Drosophila mutants to investigate the effect of disuse on the maintenance of muscle. J. Insect Physiol., 22, 1159-1165.

EASTWOOD, W. L. AND BURNET, B. 1977. Courtship latency in male Drosophila melanogaster. Behav. Genet., 7, 359-372.

EWING, A. W. 1963. Attempts to select for spontaneous activity in Drosophila melanogaster. Anim. Behav., 11, 369-378.

HALL, J. C. 1982. Genetics of the nervous system in Drosophila. Quart. Rev. Biophys., 15, 223-479.

HALL, J. C. 1985. Genetic analysis of behavior in insects. In Kerkut, G. A. and Gilbert, L. I. Comprehensive Insect Physiology Biochemistry and Pharmacology, vol. 9, Pergamon, Oxford, pp. 287-383.

HOMYK, T. 1977. Behavioral mutants of Drosophila melanogaster. II. Behavioral analysis and focus mapping. Genetics, 87, 105-128.

HOMYK, T. AND SHEPPARD, D. E. 1977. Behavioral mutants of Drosophila melanogaster. I. Isolation and mapping of mutations which decrease flight ability. Genetics, 87, 95-104.

HOMYK, T., SZIDONYA, J. AND SUZUKI, D. T. 1980. Behavioral mutants of Drosophila melanogaster. III. Isolation and mapping of mutations by direct visual observations of behavioral phenotypes. Molec. gen. Genet., 177, 553-565.

KAPLAN, W. D. 1977. iav: inactive. Drosophila Inform. Serv., 52, 1.

KONOPKA, R. J. AND BENZER, S. 1971. Clock mutants of Drosophila melanogaster. Proc. natn. Acad. Sci. USA, 68, 2112-2116.

LEFFELAAR, D. AND GRIGLiATTI, T. A. 1980a. A mutation of Drosophila that appears to accelerate ageing. Devel. Genet., 4, 199-210.

LEFFElAAR, D. AND GRIGliatti, T. A. 1980b. Age-dependent behaviour loss in Drosophila melanogaster. Develop. Genet., 4, 211-227.

LINDSLEY, D. AND ZIMM, G. 1985. The genome of Drosophila melanogaster. Drosophila Inform. Serv., 62, 1-277.

MEEHAN, M. J. AND WILSON, R. 1987. Locomotor activity in the Tyr-1 mutant of Drosophila melanogaster. Behav. Genet. 17, 503-512.

O'DELL, K. M. C. AND BURNET, B. 1986. Allelism of the behavioural mutants hypoactive $B^{1}$ and inactive in $D$. melanogaster. Drosophila Inform. Serv., 63, 107-108. 
O'DELl, K., COUlon, J.F., DAVID, J.C., PAPIN, C., FuzeauBRAESCH, S. AND JALLON, J-M. 1987. La mutation inactive produit une diminution marquee d'octopamine dans la cerveau des Drosophiles. C. R. Acad. Sci. Paris, t 305, Serie III, 199-202.

SCHÖNE, H. 1984. Spatial Orientation. Princeton University Press, Princeton, N. J.

THOMAS, J. B. 1980. Mutations affecting the giant fibre system of Drosophila. Neurosci. Abstr., 6, 742.

THOMAS, J. B. AND WYMAN, R. J. 1982. A mutation in Drosophila alters normal connectivity between two identified neurones. Nature, 298, 650-651.
VAN DIJKEN, F. R. 1982. Genetic apsects of locomotor activity of the fruitfly Drosophila melanogaster. Unpublished Doctor Thesis, Rijksuniversiteit te Utrecht.

VAN DIJKEN, F. R., STOLWIJK, H. AND SCHARLOO, W. 1987. Locomotor activity in Drosophila melanogaster. Neth. J. Zool., 35, (3), 438-454.

YU, Q., COLOT, H. V., KYRIACOU, C. P., HALl, J. C. AND ROSBASH, M. 1987. Behaviour modification by in vitro mutagenesis of a variable region within the period gene of Drosophila. Nature, 326, 865-769. 